\title{
Enhance the figure of merit for flexible thermoelectric materials by reducing the screening effect
}

\author{
Mukhlis M. Ismail ${ }^{1}$ Ahmed M. Hussein ${ }^{1}$
}

Received: 1 March 2017 / Accepted: 2 April 2017/Published online: 7 April 2017

(c) The Author(s) 2017. This article is an open access publication

\begin{abstract}
A flexible thermoelectric materials (FTEM) films based on Polydimethylsiloxane as the polymer matrix and (Zinc Oxide, Polyaniline and multi wall Carbon nanotube) as the fillers were prepared. The fillers were prepared using modified sol-gel method to enhance the distribution of the nanoparticles inside the polymer matrix and good performance. The Seebeck coefficient, electrical conductivity, thermal conductivity and dielectric measurements were carried out for all of the four films. The Seebeck coefficient results for the investigated films were $-40,220,-120,280 \mu \mathrm{v} / \mathrm{k}^{\circ}$ at $200{ }^{\circ} \mathrm{C}$ for FTEM $1,2,3,4$ alternatively. The sign and the value for the Seebeck measurements show a great dependent on the filler type add to the film. The electrical conductivity results for the films was varied from $2 \times 10^{-8}$ to $0.14 \mathrm{~S} / \mathrm{m}$ and strongly dependent on the fillers electrical conductivity. The less dependent on the thermal conductivity of the fillers and a slight change in the thermal conductivity value of the films were obtained. The figure of merit for the films was ranged from $1.14 \times 10^{-16}$ to $3.134 \times 10^{-8}$. The dielectric results ranged from 4 to 3500 . Reducing the screening effect will increase the electrical conductivity and Seebeck coefficient values.
\end{abstract}

Keywords Flexible thermoelectric nanogenerator . PDMS - Seebeck coefficient - Thermal conductivity

Mukhlis M. Ismail mmismai1009@gmail.com

1 Department of Applied Science, University of Technology, Baghdad, Iraq

\section{Introduction}

Energy harvesting converts different types of energy into electric energy. These energies can be found everywhere in nature such as mechanical, light and thermal energies all of these energies can be converted to electricity via different mechanisms (Hicks et al. 1996; Candolfi et al. 2011; Vaqueiro and Powell 2010).

Thermal energy is one of the most popular energy sources for generating electricity and can be considered as the most used method for generating electricity. Different method used to convert thermal energy to electricity and they can be divided into two methods. The first one is the conversion of thermal energy into mechanical energy then mechanical energy convert to electrical energy for example, burning fuel in electric power station and nuclear reactor. The second one is the direct generating of electricity from thermal energy via Seebeck effect; this method can be used to directly convert thermal energy in our bodies, in different layer of the earth (geothermal) and in some radioisotope materials into direct electricity. The conversion efficiency of thermal to electrical energy in Seebeck effect depends on the figure of merit (ZT). Figure of merit depend on three parameters (electrical conductivity, thermal conductivity and Seebeck coefficient). The problem in developing a new material that has high figure of merit (i.e., high conversion efficiency) is the direct dependence of these parameters on each other. Last decades scientist found a suitable way to enhance one or two of these parameters independently on the other parameters using quantum effect that been formed in different shapes of nano materials (Hsu et al. 2004; Sales 2007; Pichanusakorn and Bandaru 2010; Gibson 2010; Liang et al. 2011). 
The screening effect reduces the electrostatic field and Coulomb potential of an ion in semiconductor or metal material by electron clouds. The formation of the built-in electric field near the $\mathrm{p}-\mathrm{n}$ junction boundary will effectively deplete excess electrons in n-type material and excess holes in p-type material; this will result in reducing the screening effect and increase the electric field. Different researches have been done to enhance the output power of piezoelectric generator by utilizing the reduction of screening effect between p-type and n-type materials (Shin et al. 2013; Lei et al. 2015). Other research in enhance piezoelectric nanogenerator output power was done by incorporating high electrical conductivity material like MWCNT (Sun et al. 2013) and PANI as an alternative to MWCNT (Sultana et al. 2015) to make electrical bridge in the polymer matrix. On the other hand, the modification of thermoelectric output power was focused on making thermoelectric paste material consist of p-type material and polymer matrix (Andrei et al. 2014) or adding conductive filler to the thermoelectric paste to enhance the figure of merit by increasing the electrical conductivity (Andrei et al. 2016; Luo et al. 2016). The MWCNT filler was investigated in many researches. The thermoelectric performance of functionalized and non-functionalized MWCNT polymer composite shows little difference (Liebscher et al. 2014). Other research investigated the thermoelectric performance of PANI with MWCNT which show a great enhancement in figure of merit (Chatterjee et al. 2016).

In this work, a new method was investigated to enhance the figure of merit by increasing both Seebeck coefficient and electrical conductivity through the reduction of the screening effect. The polymer matrix shows an important role in maintaining low thermal conductivity for the films and also gives the films a flexible feature.

\section{Experimental section}

Materials used in the preparation of the FTEM films are: sol-gel synthesized ZnO, PANI from Panichem Company, MWCNT from cheap tube Company, tetrahydrofuran (THF) and PDMS Slygard 184 from Dow Corning Company.

\section{Preparation of the $\mathrm{ZnO}$ nanoparticle}

Materials used in the preparation of the $\mathrm{ZnO}$ are: Zinc nitrate hexahydrate, Cetrimonium bromide, Lithium hydroxide monohydrate, and ethanol.

First dissolve the Zinc Nitrate into $100 \mathrm{ml}$ ethanol to get a molarity of $(0.86 \mathrm{M})$ then add to the solution $0.08 \mathrm{~g}$ of
Cetrimonium bromide to help prevent the formation of agglomeration when add the lithium hydroxide solution. Then dissolve the lithium hydroxide into $100 \mathrm{ml}$ ethanol at $0{ }^{\circ} \mathrm{C}$ to get $(1.7 \mathrm{M})$ solution, and then dropwise add the lithium hydroxide solution into the Zinc Nitrate solution with continuous stirring at $60{ }^{\circ} \mathrm{C}$ for $1 \mathrm{~h}$. After filtering white precipitate powder was obtained and dried in the furnace for about $4 \mathrm{~h}$ at $500{ }^{\circ} \mathrm{C}$, after that washed, filtered and dried the powder to get the final $\mathrm{ZnO}$ powder.

\section{Functionalization of the MWCNT}

Materials used in the MWCNT functionalization process are: MWCNT, Sulfuric acid $\left(\mathrm{H}_{2} \mathrm{SO}_{4}\right)$, Hydrochloric acid $(\mathrm{HCl})$, Nitric acid $\left(\mathrm{HNO}_{3}\right)$, Sodium hydroxide $(\mathrm{NaOH})$ and water.

First mix $25 \mathrm{ml}$ of $\mathrm{HNO}_{3} 68 \%$ concentration with $75 \mathrm{ml}$ of $\mathrm{H}_{2} \mathrm{SO}_{4} 98 \%$ concentration then added $1 \mathrm{~g}$ of MWCNT and mix the solution for $1 \mathrm{~h}$ using ultrasonic device and then leave the mixture for $19 \mathrm{~h}$ then after that add $40 \mathrm{ml}$ of concentrated $\mathrm{HCl}$ to the solution and mix using ultrasonic for $1 \mathrm{~h}$ then add $120 \mathrm{ml}$ of $(4 \mathrm{M}) \mathrm{NaOH}$ solution to the solution above to get a $\mathrm{pH}$ of about 7 then filter the solution using the vacuum pump and wash the powder with distilled water then dry the solution at $80{ }^{\circ} \mathrm{C}$ for $2 \mathrm{~h}$.

\section{Preparation of the FTEM films}

FTEM 1 was prepared by dispersion of $10 \%$ wt of $\mathrm{ZnO}$ into $5 \mathrm{ml}$ of THF and then mixed with the solution using ultrasonic device. A solution of $90 \%$ wt of PDMS and $5 \mathrm{ml}$ of THF was mixed ultrasonically then add the PDMS solution to $\mathrm{ZnO}$ solution with mechanically stirring for $1 \mathrm{~h}$ at $70{ }^{\circ} \mathrm{C}$ to get a uniform solution then let the mixture cooled to room temperature and left it for 1 day to complete the evaporation of the THF. After evaporation of the THF, the PDMS composite was mixed in wt ratio 16:1 with the curing agent with continuous stirring. After that the composite was drop casted on glass substrate and set to $70{ }^{\circ} \mathrm{C}$ for $2 \mathrm{~h}$ to cure. Then the film was annealed at $140{ }^{\circ} \mathrm{C}$ for $4 \mathrm{~h}$.

FTEM 2 was prepared by dispersion of $10 \%$ wt of $\mathrm{ZnO}$ and $20 \%$ wt of PANI into $5 \mathrm{ml}$ of THF and then mixed the solution using ultrasonic device. A solution of $70 \% \mathrm{wt}$ of PDMS and $5 \mathrm{ml}$ of THF was mixed ultrasonically then add the PDMS solution to $\mathrm{ZnO}$ solution with mechanically stirring for $1 \mathrm{~h}$ at $70{ }^{\circ} \mathrm{C}$ to get a uniform solution then let the mixture cooled to room temperature and left it for 1 day to complete the evaporation of the THF. After evaporation of the THF, the PDMS composite was mixed in wt ratio 16:1 with the curing agent with continuous 
stirring. After that the composite was drop casted on glass substrate and set to $70{ }^{\circ} \mathrm{C}$ for $2 \mathrm{~h}$ to cure. Then the film was annealed at $70{ }^{\circ} \mathrm{C}$ for $4 \mathrm{~h}$.

FTEM 3 was prepared by dispersion of $10 \%$ wt of $\mathrm{ZnO}$, $0.8 \%$ wt F-MWCNT and $0.8 \%$ wt MWCNT into $5 \mathrm{ml}$ of THF and then mixed the solution using ultrasonic device. A solution of $88.4 \%$ wt of PDMS and $5 \mathrm{ml}$ of THF was mixed ultrasonically then added the PDMS solution to $\mathrm{ZnO}$ solution with mechanically stirring for $1 \mathrm{~h}$ at $70{ }^{\circ} \mathrm{C}$ to get a uniform solution then let the mixture cooled to room temperature and left it for 1 day to complete the evaporation of the THF. After evaporation of the THF, the PDMS composite was mixed in wt ratio 16:1 with the curing agent with continuous stirring. After that the composite was drop casted on glass substrate and set to $70{ }^{\circ} \mathrm{C}$ for $2 \mathrm{~h}$ to cure. Then the film was annealed at $140{ }^{\circ} \mathrm{C}$ for $4 \mathrm{~h}$.

FTEM 4 was prepared by dispersion of $10 \%$ wt of $\mathrm{ZnO}$, $20 \%$ wt of PANI, $0.8 \%$ wt F-MWCNT and $0.8 \%$ wt MWCNT into $5 \mathrm{ml}$ of THF and then mixed the solution using ultrasonic device. A solution of $68.4 \%$ wt of PDMS and $5 \mathrm{ml}$ of THF was mixed ultrasonically then added the PDMS solution to $\mathrm{ZnO}$ solution with mechanically stirring for $1 \mathrm{~h}$ at $70{ }^{\circ} \mathrm{C}$ to get a uniform solution then let the mixture cooled to room temperature and left it for 1 day to complete the evaporation of the THF. After evaporation of the THF, the PDMS composite was mixed in wt ratio 16:1 with the curing agent with continuous stirring. After that the composite was drop casted on glass substrate and set to $70{ }^{\circ} \mathrm{C}$ for $2 \mathrm{~h}$ to cure. Then the film was annealed at $70{ }^{\circ} \mathrm{C}$ for $4 \mathrm{~h}$. The digital photos for four prepared films are shown in Fig. 1.

\section{Characterization}

The crystal structure for the $\mathrm{ZnO}$ film was measured by XRD device (D/Max-RB Model). The electrical conductivity for the films was carried out with two-point electrical

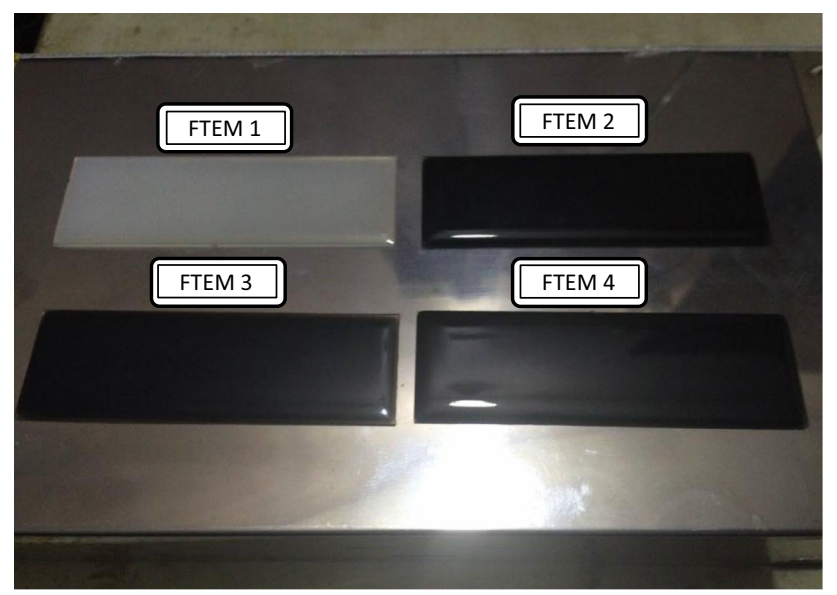

Fig. 1 The digital photo of FTEM films resistance method using digital multimeter (twintex TM$8155)$ as the resistance measurement unit and heat source, the measurements temperature was from room temperature 26 to $200{ }^{\circ} \mathrm{C}$. The Seebeck coefficient measurement was carried out by homemade setup as shown in Fig. 2; which consists of digital multimeter (twintex TM-8155) as the voltage measurement unit, digital thermometer, AC dimmer circuit and $500 \mathrm{~W}$ heating element. The films dimension is $(6 \times 2.5) \mathrm{cm}^{2}$ and the copper tape electrode was attached to both end sides. The distance between the hot and cold side was set to $1.5 \mathrm{~cm}$. The thermo voltage was recorded every $5{ }^{\circ} \mathrm{C}$ temperature difference between the hot and cold side and the temperature range was from room temperature to $200{ }^{\circ} \mathrm{C}$. The Seebeck coefficient was determined from the formula below:

$S=-\left(\frac{\Delta V}{\Delta T}\right)$

where $S$ is the Seebeck coefficient, $\Delta V$ is the thermo voltage and $\Delta T$ is the temperature difference between the two ends of a film. The highest values recorded for Seebeck coefficient and electrical conductivity was taken at $200{ }^{\circ} \mathrm{C}$ for all films, for this reason the values of other temperature are not recorded.

The thermal conductivity measurements for FTEM films was carried out using Lee's disk method, the films were put between two brass plate (plate a, plate b). The heat source for the experiment was the constant voltage and current of $6 \mathrm{~V} 0.25 \mathrm{~A}$, respectively. The thermal conductivity equation is shown below:

$$
\begin{aligned}
H= & I . V \\
= & \pi r^{2} e\left(T_{A}+T_{B}\right) \\
& +2 \pi r e\left(d_{A} T_{A}+d_{S} \frac{1}{2}\left(T_{A}+T_{B}\right)+d_{B} T_{B}+d_{C} T_{C}\right)
\end{aligned}
$$

where $H$ is the average time of the applied energy to heat the coil, $\left(T_{A}, T_{B}, T_{C}\right)$ is the $(A, B, C)$ disk's temperature, respectively, $\left(d_{A}, d_{B}, d_{C}\right)$ is the $(A, B, C)$ disk's thickness, respectively, $d_{S}$ is the Sample $S$ thickness, $r$ is the disk diameter, $I$ is the current flow, $V$ is the supply voltage

$K\left(\frac{T_{B}-T_{A}}{d_{S}}\right)=e\left(T_{A}+\frac{2}{r}\left(d_{A}+\frac{d_{S}}{4}\right) T_{A}+\frac{1}{2 r} d_{S} T_{B}\right)$

where $e$ is the amount of the thermal energy flows over disk' cross section for every second and $K$ is the thermal conductivity.

The dielectric constant measurement for the FTEM films was carried out by LCR meter using (Gw-insteck LCR$8105 \mathrm{G})$ device at room temperature.

The dielectric constant for the FTNG films was evaluated from equation below: 
Fig. 2 Seebeck coefficient measurement schematic

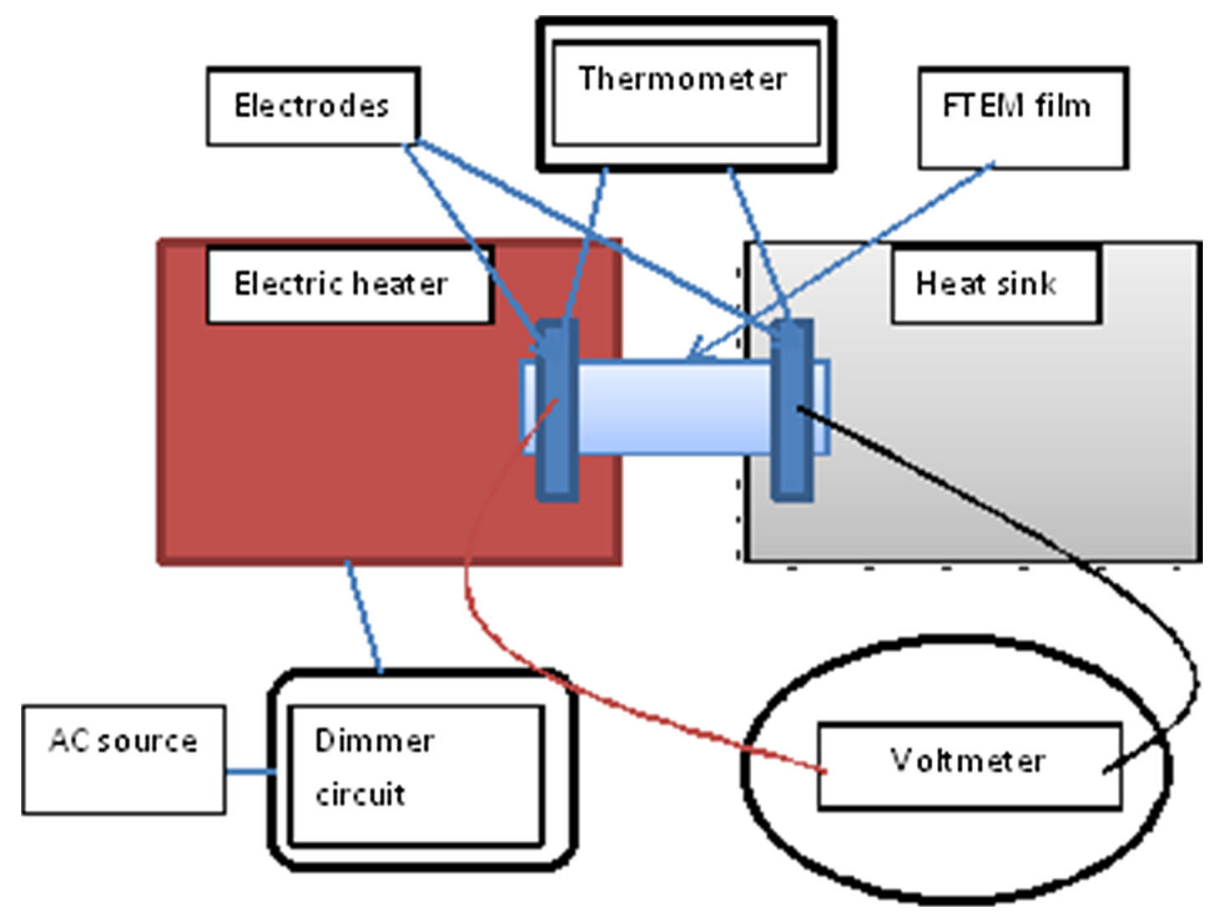

$C=\frac{\varepsilon_{0} \varepsilon_{r}}{d} \cdot A$

where $\varepsilon_{0}$ is the dielectric constant of the free space, $A$ is the area of the electrical conductor, $d$ is the thickness of the dielectric layer, and $\varepsilon_{\mathrm{r}}$ is the dielectric constant.

\section{Result and discussion}

\section{XRD}

Figure 3 shows the $\mathrm{ZnO}$ nanoparticle have a polycrystalline structure and the characteristic peaks of the $\mathrm{ZnO}$ occur at $2 \theta=(31.8596,34.5275,36.3581,47.6471$, $56.7023,62.9798,66.4780,68.0460,69.1904)$ which correspond to the miller indices $(100,002,101,102,110,103$, 200, 112, 201), respectively. All the observed diffraction peaks are indicating the formation of hexagonal phase of

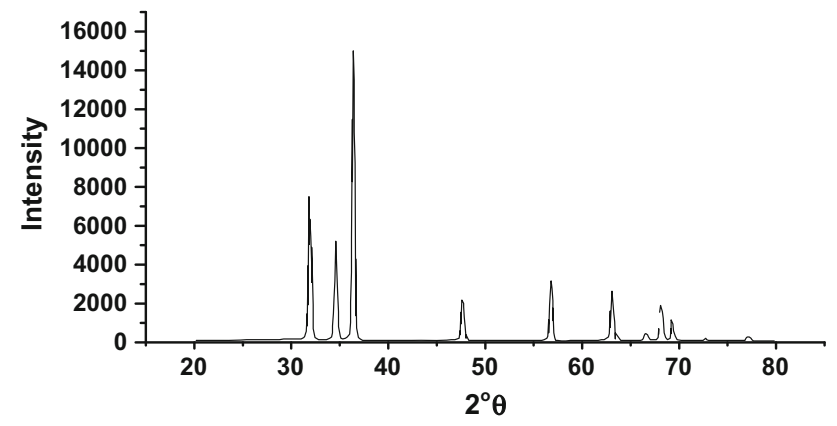

Fig. $3 \mathrm{XRD}$ of the $\mathrm{ZnO}$ nanoparticle the $\mathrm{ZnO}$. There are no peaks of impurities observed, which means that the $\mathrm{ZnO}$ nanoparticle with high purity was obtained (Kolekar et al. 2011). The average crystallite size of the $\mathrm{ZnO}$ was calculated using Scherrer equation. The average crystallite size of the $\mathrm{ZnO}$ nanoparticle $D$ was found to be $19.5 \mathrm{~nm}$.

\section{Electrical conductivity}

Figure 4 shows the electrical conductivity of the four FTEM films at $200{ }^{\circ} \mathrm{C}$. The result show large difference in electrical conductivity between the FTEM films; the reason could be related to the conductivity of the filler added to the film. The reason for increasing the electrical conductivity of the FTEM films can be assigned to hopping and tunneling effect (Khanam et al. 2015), also the high concentration of the fillers inside the insulating matrix could lead to physical interaction between the adjacent particles thus increase the electrical conductivity.

\section{Thermal conductivity}

Figure 5 shows the thermal conductivity of the four FTEM films. The thermal conductivity results show slight increases in value between the FTEM films; although the fillers ( $\mathrm{ZnO}, \mathrm{MWCNT})$ have high thermal conductivity. This small influence of the high thermal conductivity filler on the overall thermal conductivity of the polymer Nano composites can be assigned to the fact that the thermal conductivity of the polymer nano composites is highly 


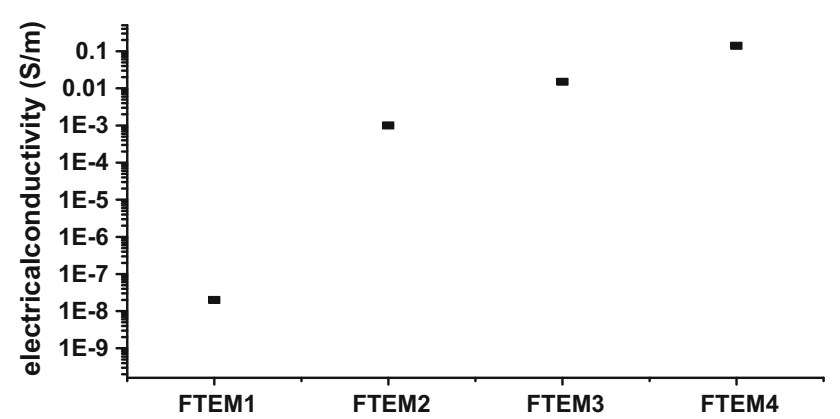

Table 1 The value of Seebeck coefficient for the FTEM films at $200{ }^{\circ} \mathrm{C}$

\begin{tabular}{lc}
\hline Film & $\begin{array}{l}\text { Seebeck coefficient } \\
S\left(\mu \mathrm{v} / \mathrm{k}^{\circ}\right)\end{array}$ \\
\hline FTEM 1 & -40 \\
FTEM 2 & 220 \\
FTEM 3 & -120 \\
FTEM 4 & 280 \\
\hline
\end{tabular}

Fig. 4 The electrical conductivity of the FTEM films at $200{ }^{\circ} \mathrm{C}$

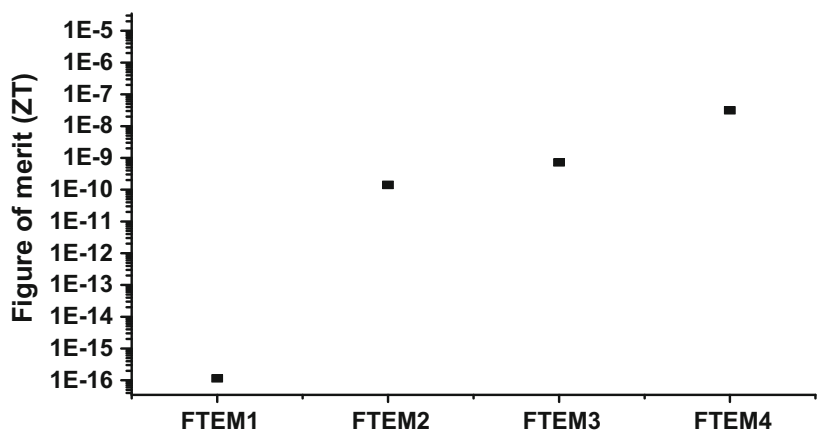

Fig. 6 Figure of merit for the FTEM films

Fig. 5 Thermal conductivity of the FTEM films

affected by phonon scattering with polymer chains (Choi et al. 2011). The agglomeration of MWCNT filler in the FTEM films due to the fact that CNT are self-agglomerated this could lead to dissipationb of heat by randomly formed phonon trajectories (Hong et al. 2010). Lastly for the FTEM films that contain the PANI filler the thermal conductivity slight change due to low thermal conductivity PANI filler.

\section{Seebeck coefficient}

Table 1 shows the Seebeck coefficient for the four FTEM films at $200{ }^{\circ} \mathrm{C}$. FTEM 1 and 3 films Seebeck coefficient sign show negative sign; this may be due to the dominance of electrons carrier result from higher concentration of $\mathrm{ZnO}$ filler inside the polymer matrix. The FTEM 2 and 4 films Seebeck coefficient sign show positive sign; this may be due to the dominance of holes carrier result from higher concentration of the PANI filler inside the polymer matrix. FTEM 1 film shows lower Seebeck coefficient compare to the $\mathrm{ZnO}$ bulk or nanoparticle; The reason for this can be assigned to the restricted movement of the charge carrier inside the insulating polymer matrix that increase the losses of the thermally energized charge carrier. The FTEM 2 film shows a large increase in the Seebeck coefficient; this can be assigned to the decrease of the electrical resistivity of the FTEM films by the high conductivity of the PANI filler (Luo et al. 2016). Another reason for increasing Seebeck

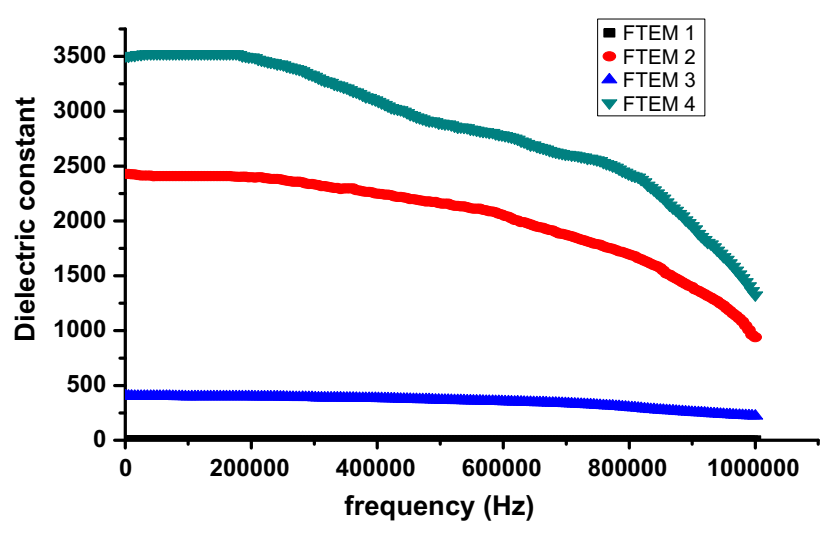

Fig. 7 Dielectric constant of the FTEM films

coefficient of FTEM 2 film can be subjected to reduce the screening effect for PANI filler (Lei et al. 2015). The FTEM 3 film shows a moderate enhancement in the Seebeck coefficient; this can be assigned to the high electrical conductivity of MWCNT filler. The high electrical conductivity will form an electrical network inside the polymer; this will give the charge carrier more chance to find an easy path to travel from hot to cold side thus increase the Seebeck coefficient.

Finally, FTEM 4 film shows the highest Seebeck coefficient value; the reason can be subjected to decrease of excess carrier concentration by the screening effect and enhance the flow of charge carrier.

The higher the capacitance (dielectric constant) will tend to increase the repulsive electrostatic force build up

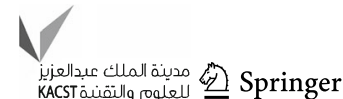


from charges formed at the cold side thus increase number of difference in charged carrier between hot and cold side [i.e., electric field (Seebeck coefficient)]. This will lead to push larger number of charges back to the hot side (Yu and Chau 2009; Kittel and Kroemer 1980).

\section{Figure of merit}

Figure 6 shows the figure of merit for the four FTEM films. The value of the figure of merit show great enhancement by adding of conductive filler to the films as shown in FTEM 1, 2, 3, 4 films. The highest $\mathrm{ZT}$ value achieved is $3.134 \times 10^{-8}$. On the other hand, the decrease of the screening effect leads to great enhancement in the ZT value by order of 8 which can be considered new way to develop a high ZT value composite.

\section{Dielectric constant}

Figure 7 show the dielectric constant of FTEM films with frequency. In the low frequency region the dielectric constants have the maximum value and at high frequency region the value of the dielectric is the lowest. This behaviour can be explained by the relaxation time theory (Dutta et al. 2002) that states at the low frequency region there is enough time for the dipole to align themselves with the electric field before field goes opposite direction. For the high frequency region the decrease was due to the dipoles cannot align themselves probably as to keep tracking the change in electric field frequency.

The FTEM 1 film shows an increase in the value of the dielectric constant; this may attribute to formation of interfacial polarization between $\mathrm{ZnO}$ and the polymer and also the increase could be attributed to the higher dielectric constant of the $\mathrm{ZnO}$ compare to PDMS.

The FTEM 2 film shows a sharp increase in the dielectric constant, this may be subjected to the formation of mini capacitor inside the polymer matrix. The sharp increase may also attribute to the formation of $\mathrm{p}-\mathrm{n}$ junction (between $\mathrm{ZnO}$ and PANI inside PDMS matrix) that will increase the dielectric constant by reducing screening effect (Ho et al. 2008).

The FTEM 3 film shows a great enhancement of the dielectric constant; this result can be assigned to the formation of mini capacitor by the MWCNT and the polymer matrix or the $\mathrm{ZnO}$ filler. Under the applied electric field the charge are accumulated on the nanotube where the MWCNT serve as a secondary electrode (Poh et al. 2016).

Finally the FTEM 4 film show a large enhancement in the dielectric constant, the reason also can be assigned to the increase in the number of the mini capacitor formed inside the polymer and the interfacial polarization of the filler-filler interaction and the polymer matrix-filler interaction.

\section{Conclusion}

Simple sol-gel method is used to synthesis of flexible thermoelectric material films consist of cheap and nontoxic materials. The thermoelectric and dielectric properties for the films were done. The influence of the screening effect on the thermoelectric parameter Seebeck coefficient and electrical conductivity was investigated for all the films. The Seebeck coefficient value and sign of the films show a great dependent on the filler type; the highest value reaches $280 \mu \mathrm{v} / \mathrm{k}^{\circ}$. The electrical conductivity of the films enhances dramatically with conductive fillers; the highest value achieved is $0.14 \mathrm{~S} / \mathrm{m}$; on the other hand, the thermal conductivity is less influenced by fillers and maintains low thermal conductivity value of less than $0.5 \mathrm{~W} / \mathrm{mk}^{\circ}$. The figure of merit also shows a dramatical enhancement though it still has very low value of about $3.134 \times 10^{-8}$; the overall enhancement was very sharp. The dielectric results of the films show great enhancement by adding conductive filler to them due to formation of mini capacitor. On the other hand, it was suggested that another reason for increase in the Seebeck coefficient is the high capacitance of the FTEM films.

Open Access This article is distributed under the terms of the Creative Commons Attribution 4.0 International License (http:// creativecommons.org/licenses/by/4.0/), which permits unrestricted use, distribution, and reproduction in any medium, provided you give appropriate credit to the original author(s) and the source, provide a link to the Creative Commons license, and indicate if changes were made.

\section{References}

Andrei V, Bethke K, Rademann K (2014) Copper (I) oxide based thermoelectric powders and pastes with high Seebeck coefficients. Appl Phys Lett 105:233902

Andrei V, Bethke K, Rademann K (2016) Adjusting the thermoelectric properties in copper (I) oxide-graphite-polymer pastes and the applications of such flexible composites. Phys Chem Chem Phys 18(16):10700-10707

Candolfi C, Aydemir U, Ormeci A, Baitinger M, Oeschler N, Steglich F, Grin Yu (2011) Low-temperature magnetic, galvano magnetic, and thermoelectric properties of the type-I clathrates Ba 8 $\mathrm{Ni} \times \mathrm{Si}$ 46- X. Phys Rev B 83(20):205102

Chatterjee MJ, Banerjee D, Chatterjee K (2016) Composite of single walled carbon nanotube and sulfosalicylic acid doped polyaniline: a thermoelectric material. Mater Res Express 3:085009

Choi Y, Kim Y, Park S et al (2011) Effect of carbon nanotube type on the thermoelectric properties of the CNT/Nafion nanocomposite. Org Electron 12:2120-2125

Dutta P, Biswas S, De SK (2002) Mater Res Bull 37:193

Gibson Ronald F (2010) A review of recent research on mechanics of multifunctional composite materials and structures. Compos Struct 92:2793-2810

Hicks LD, Harman TC, Sun X (1996) Experimental study of the effect of quantum-well structures on the thermoelectric figure of merit. Phys Rev B 53(16):R10493-R10496 
Ho CH, Liu CD, Hsieh CH, Hsieh KH, Lee SN (2008) High dielectric constant polyaniline/poly (Acrylic acid) composites prepared by in situ polymerization. Synth Met 158(15):630-637

Hong J, Lee J, Hong CK, Shim SE (2010) Curr Appl Phy 10:359

Hsu KF, Loo S, Guo F, Chen W, Dyck JS, Uher C, Hogan T, Polychroniadis EK, Kanatzidis MG (2004) Cubic Agpbmsbte2+ $\mathrm{m}$ : bulk thermoelectric materials with high figure of merit. Science. doi:10.1126/Science. 1092963

Khanam PN, Ponnamma D, AL-Madeed MA (2015) Electrical properties of graphene polymer nanocomposites. Springer International Publishing, Switzerland, pp 25-47

Kittel C, Kroemer H (1980) Thermal physics. Macmillan, London

Kolekar T, Yadav H, Bandgar S, Deshmukh P (2011) Synthesis by sol-gel method and characterization of $\mathrm{ZnO}$ nanoparticles. Ind Streams Res J 1:2-6

Lei J, Yin B, Qiu Y, Zhang H, Chang Y, Luo Y, Zhao Y, Ji J, Hu L (2015) Flexible piezoelectric nano generator based on $\mathrm{Cu}_{2} \mathrm{O}$ $\mathrm{ZnO}$ p-n junction for energy harvesting. RSC Adv. doi:10.1039/ C5RA09878E

Liang H, Cooper R, Files J (2011) Phase transformation of poly (vinylidene difluoride) in energy harvesting. J Mater Res 26(01):1-8

Liebscher M, Gärtner T, Tzounis L, Mičušík M, Pötschke P, Stamm M, Heinrich G, Voit B (2014) Influence of the MWCNT surface functionalization on the thermoelectric properties of melt-mixed polycarbonate composites. Compos Sci Technol 12(101):133-138

Luo J, Krause B, Pötschke P (2016) Melt-mixed thermoplastic composites containing carbon nanotubes for thermoelectric applications. AIMS Mater Sci 3(3):1107-1116
Pichanusakorn P, Bandaru PR (2010) Minimum length scales for enhancement of the power factor in thermoelectric nanostructures. J Appl Phys 107:074304. doi:10.1063/1.3359659

Poh CL, Mariatti M, Noor AF, Sidek O, Chuah TP, Chow SC (2016) Dielectric properties of surface treated multi-walled carbon nanotube/epoxy thin film composites. Compos Part B Eng 29(85):50-58

Sales BC (2007) Critical overview of recent approaches to improved thermoelectric materials. Int $\mathrm{J}$ Appl Ceram Technol 4(4):291-296

Shin SH, Lee MH, Jung JY, Seol JH, Nah J (2013) Piezoelectric performance enhancement of $\mathrm{ZnO}$ flexible nano generator by a $\mathrm{CuO}-\mathrm{ZnO} \mathrm{p}-\mathrm{n}$ junction formation. $\mathrm{J}$ Mater Chem $\mathrm{C}$ $1: 8103-8107$

Sultana A, Alam MM, Garain S, Sinha TK, Middya TR, Mandal D (2015) An effective electrical throughput from pani supplement zns nano rods and pdms-based flexible piezoelectric nano generator for power up portable electronic devices: an alternative of MWCNT filler. ACS Appl Mater Interfaces. doi:10.1021/ acsami.5b04669

Sun H, Tian H, Yang Y, Xie D, Zhang YC, Liu X, Ma S, Zhao HM, Ren TL (2013) A novel flexible nano generator made of $\mathrm{ZnO}$ nanoparticles and multiwall carbon nanotube. Nanoscale 5:6117-6123

Vaqueiro P, Powell AV (2010) Recent Developments In Nanostructured Materials For High-Performance Thermoelectric. J Mater Chem 20:9577-9584

Yu C, Chau K (2009) Thermoelectric automotive waste heat energy recovery using maximum power point tracking. Energy Conversat Manage 50:1506-1512 